\title{
Can gravel augmentation restore thermal functions in gravel-bed rivers? A need to assess success within a trajectory-based BACI framework
}

\author{
Baptiste Marteau ${ }^{1}$, Kristell Michel ${ }^{1}$, and Hervé Piégay ${ }^{2}$ \\ ${ }^{1} \mathrm{UMR} 5600$ \\ ${ }^{2} \mathrm{CNRS}$
}

December 26, 2020

\begin{abstract}
Gravel augmentation has become common practice to mitigate the effects of decline in upstream sediment supply in gravelbed rivers. The success of such rehabilitation schemes relies partly on the monitoring strategy and efforts. When long-term monitoring is lacking, some aspects of rehabilitation initiatives suffer more than others, such as insights into functions and functionalities of the river system. Despite temperature being a fundamental parameter determining the general health of river ecosystems, a limited number of studies have tested whether gravel-augmentation can aid restoring thermal functions. With the help of airborne thermal infrared (TIR) imagery, this paper explores the potential positive feedbacks through the monitoring of gravel augmentation actions, of different magnitude, taken on 3 rivers of the Rhône basin in France. A specific trajectory-based Before-After-Control-Impact (BACI) framework using simple indicators, combined with a TIR-based Control-Impact strategy, was designed to assess the success of thermal function restorations based on dynamic fuzzy references. Results indicate that restoring forms is not sufficient to restore thermal functions. The control-impact strategy shows limitations in the sense that two neighbouring reaches can display similar planform characteristics but different thermal functions; what is observed in a control reach should not necessarily be expected following rehabilitation. When assessing thermal processes, a before-after strategy is needed to either serve as a target or help define an adequate target in accordance with changes in the catchment and channel adjustments and responsiveness. We therefore recommend a trajectory-based BACI assessment to identify current biogeophysical conditions within which rehabilitation can be assessed. From a technical perspective, airborne TIR proved to be useful to rapidly map surface temperature over dozens of kilometres at high resolution, and can be advocated as a powerful tool to monitor and diagnose thermal functions of gravel-bed rivers. With an increasing number of rehabilitation schemes, and increasing pressure of global changes on rivers, we suggest that monitoring of water temperature, even with simple but well-designed sampling strategies, becomes a routine part of river rehabilitation projects.
\end{abstract}

\section{Hosted file}

Marteau_gravel_augmentation_temperature_final.odt available at https://authorea.com/users/ 385251/articles/500734-can-gravel-augmentation-restore-thermal-functions-in-gravel-bedrivers-a-need-to-assess-success-within-a-trajectory-based-baci-framework 


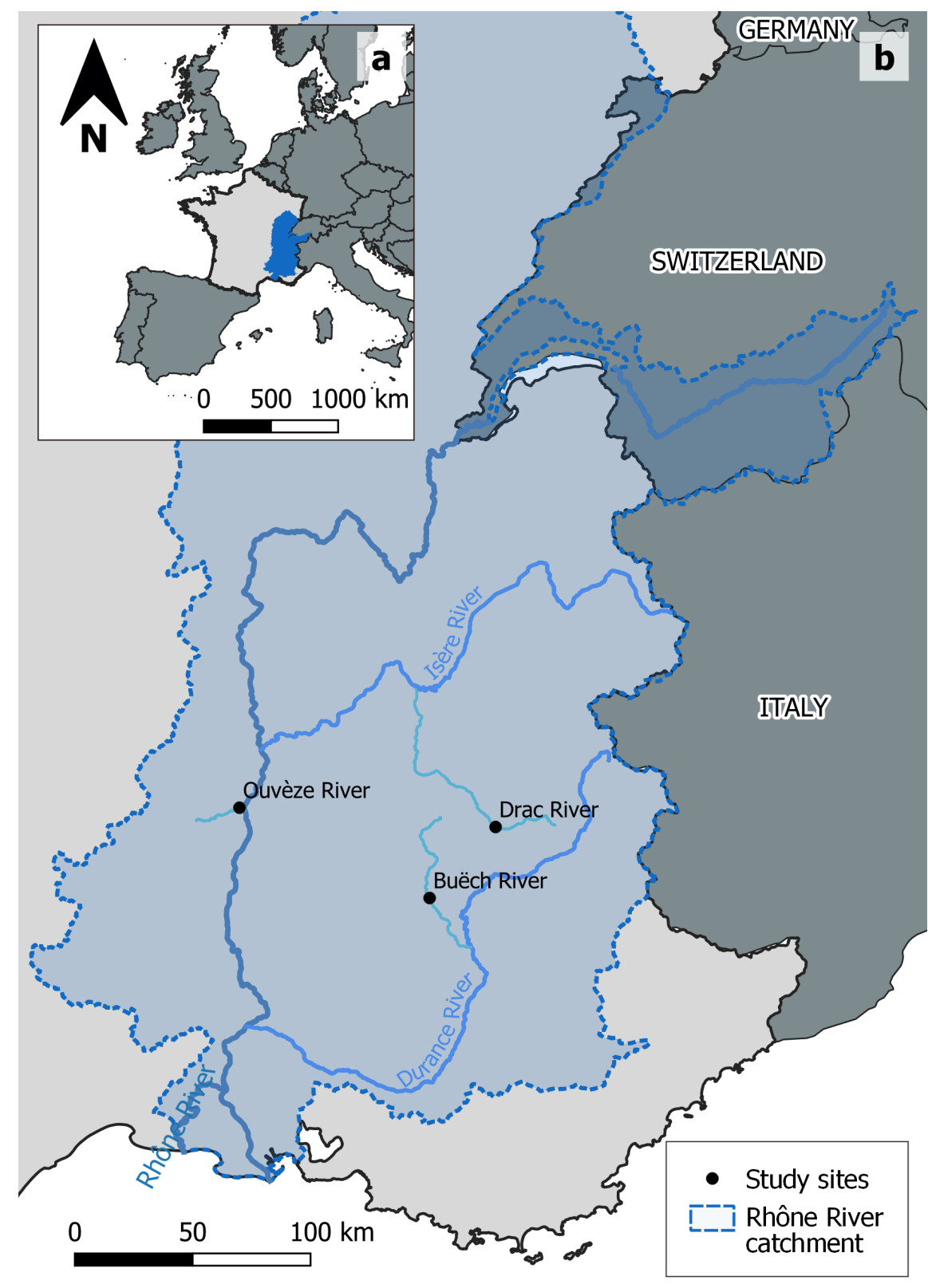



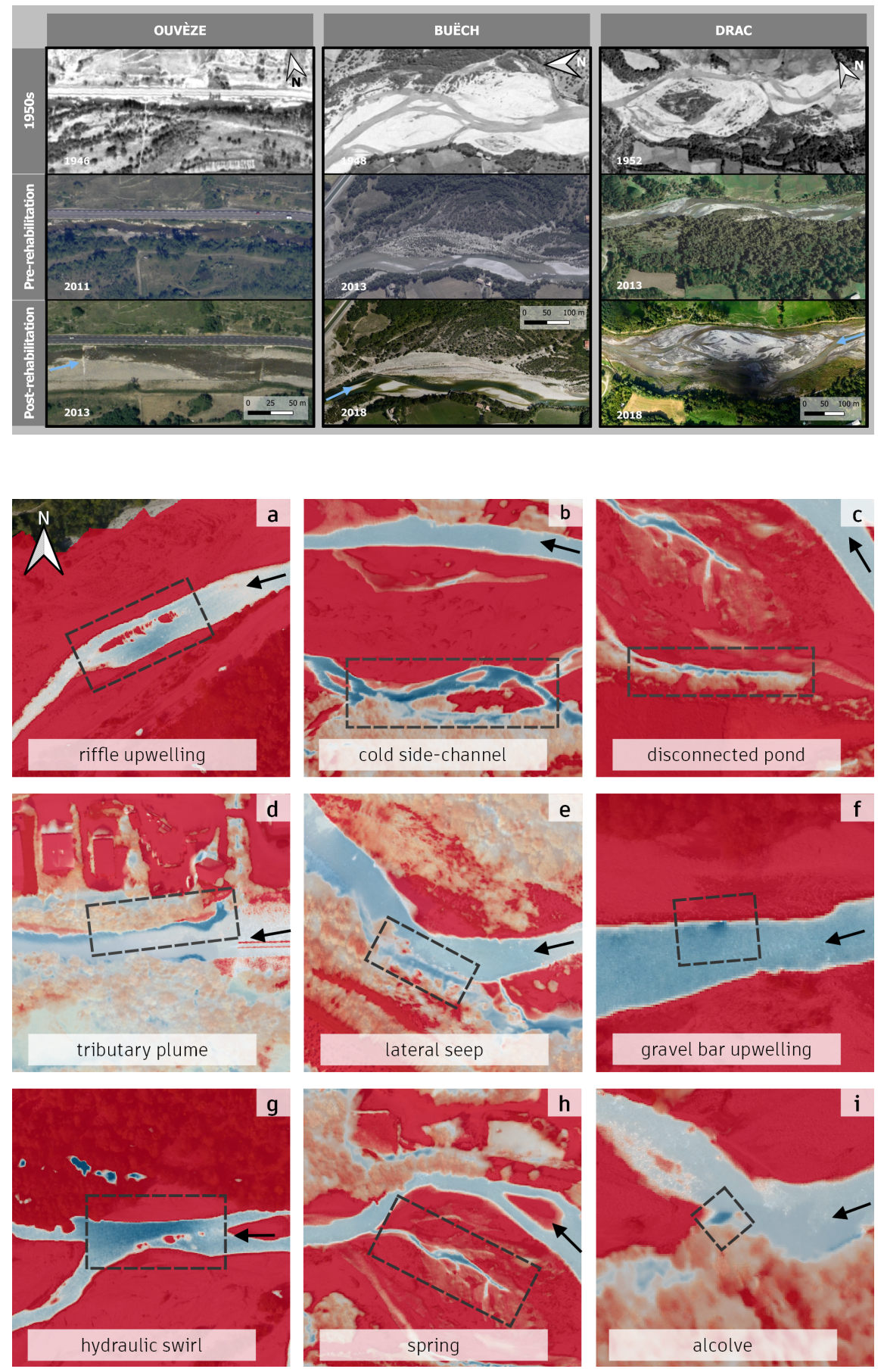


\begin{tabular}{ll}
\hline & Unaltered \\
\hline & $\begin{array}{l}\text { Proxies to } \\
\text { assess thermal } \\
\text { functions }\end{array}$ \\
\hline $\begin{array}{l}\text { TIR to assess } \\
\text { thermal } \\
\text { functions } \\
\text { Comparison } \\
\text { based on set of } \\
\text { indicators } \\
\text { Unknown degree } \\
\text { of alteration }\end{array}$ \\
\hline$?$
\end{tabular}

Single

historical

reference

Before

After

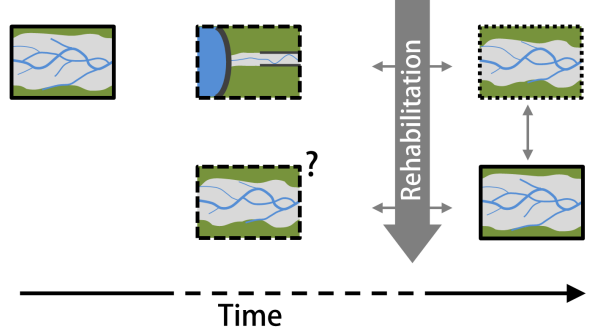

Impact

Control

Trajectory including several states (= potential historical references) Before

After

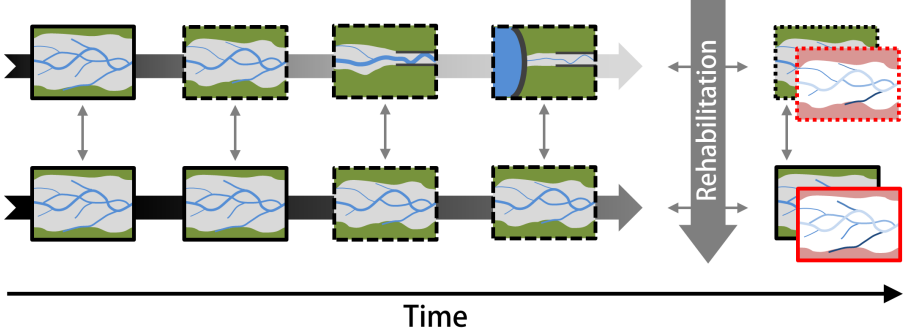

Impact

Control

(=Potential

Geographic reference)

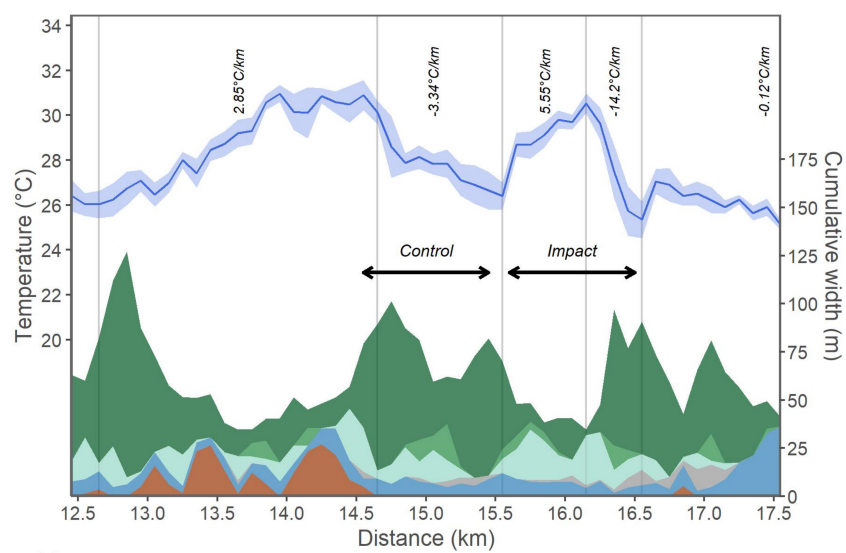

alluvial forest

vegetalised bar (stage II)

vegetalised bar (stage I)

gravel bar

wetted chanel

bedrock outcrop

Categories

riffle upwelling

cold side chanel

tributary

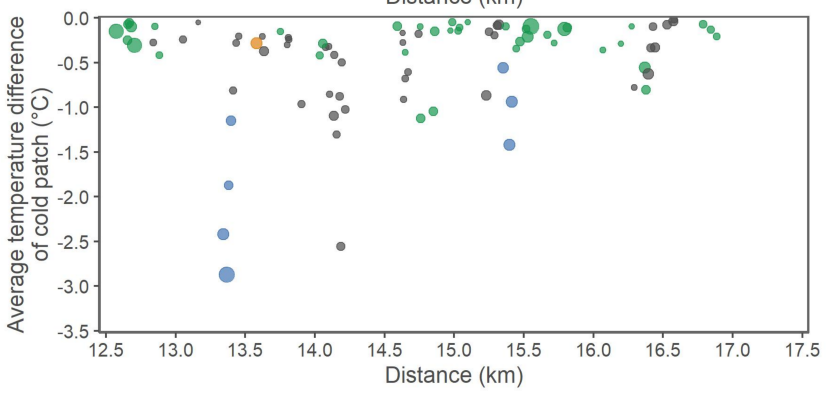

lateral seep

gravel bar upwelling

hydraulic swirl

effluent

Surface $\left(m^{2}\right)$

- 25

- 50

100 

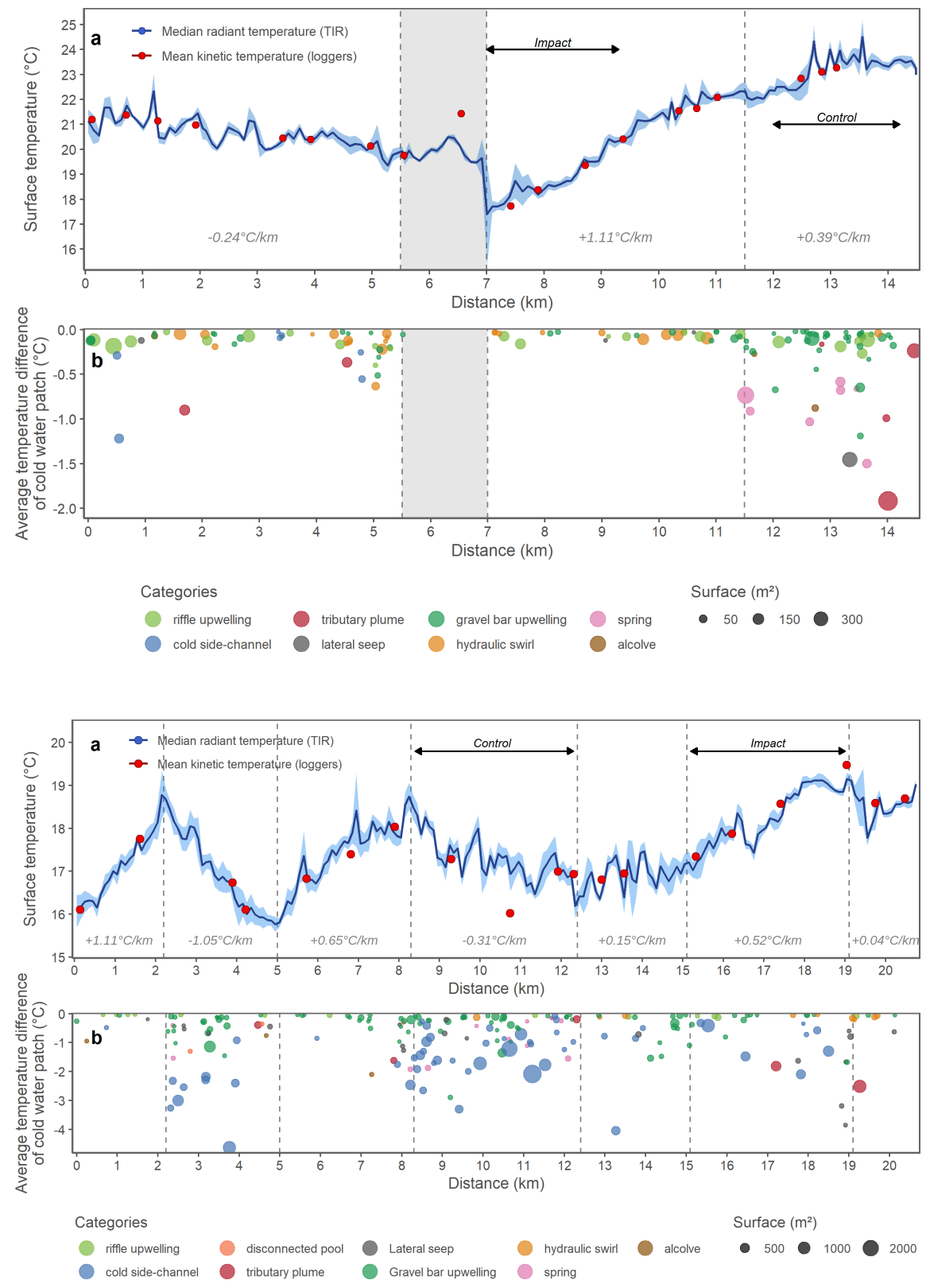

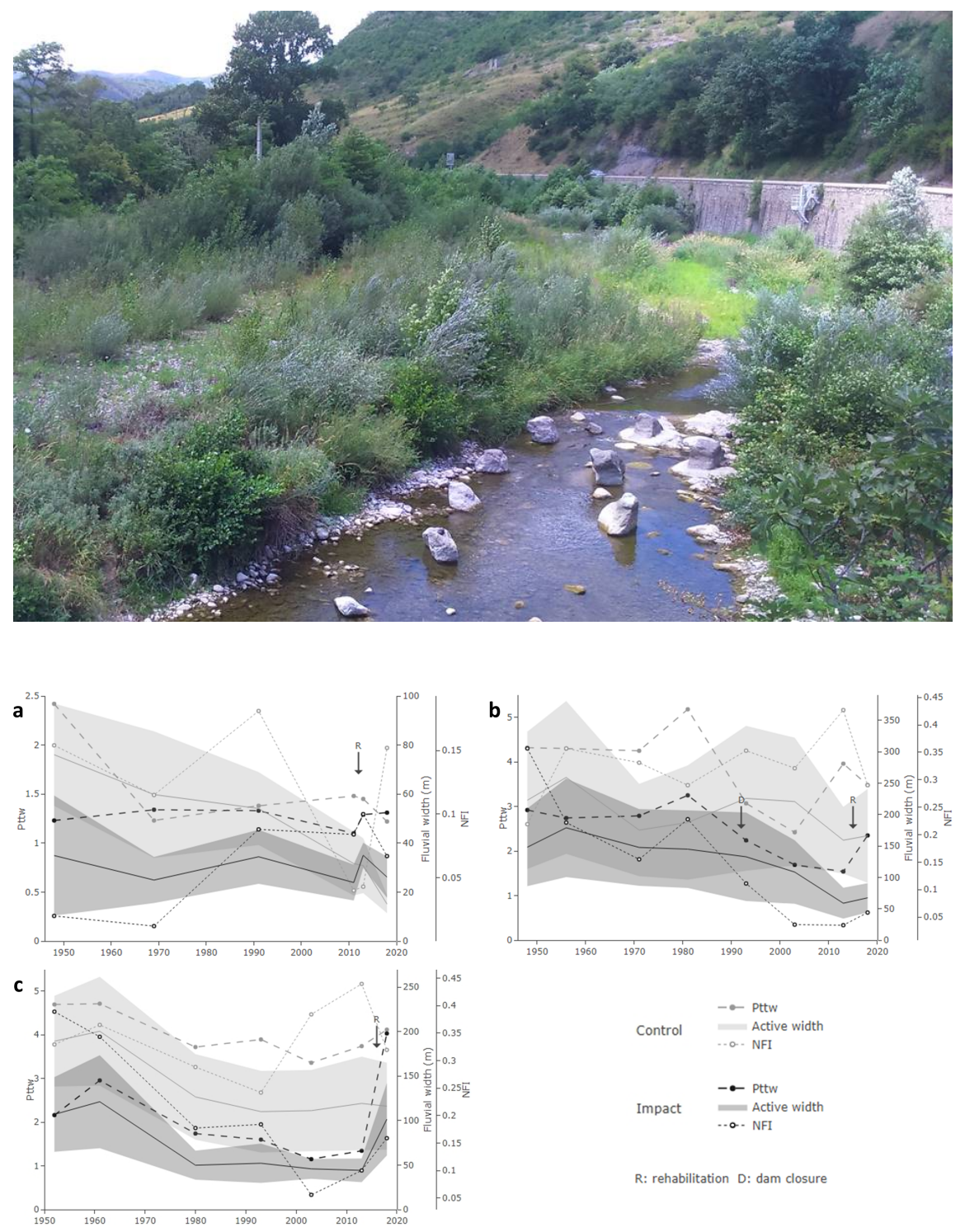